\title{
PROPUESTAS PARA EL NUEVO PARADIGMA EDUCATIVO DE LA HISTORIA'
}

\author{
Carlos Barros \\ Universidad de Santiago de Compostela
}

\section{Resumen}

Carlos Barros defiende la necesidad de un nuevo paradigma educativo de la historia en alianza con el nuevo paradigma historiográfico propuesto por la red internacional Historia a Debate, basado simultáneamente en tres ejes: 1) una educación en competencias, en el manejo de las fuentes históricas desde la enseñanza secundaria, y ajena por tanto al mercantilismo propagado de manera fundamental ista por la OCDE y otras instituciones internacionales; 2 ) una educación en valores universales desde la historia; 3) una educación crítica y plural de las historias nacionales y mundial. R eflexiones y propuestas que tienen en cuenta los debates en marcha sobre la unificación del espacio europeo de la educación superior.

\section{Palabras claves}

Paradigma • educación • historia $\bullet$ enseñanza $\bullet$ historiografia.

\section{Abstract}

Carlos Barros defends the need for a new educational paradigm of history in alliance with the new paradigm historiographical proposed by the international network History under D ebate, based simultaneously on three axes: 1) an education in competences, in handling historical sources from the secondary education, and therefore outside the spread of commercialism fundamentalist way by the OECD and other international institutions; 2) an education in universal values from history; 3 ) an educati on critique and plural of histories national and global. Reflections and proposals which takeinto account the discussions under way on the unification of the European area of higher education.

\section{Keywords}

Paradigm $\bullet$ education $\bullet$ history $\bullet$ teaching $\bullet$ historiography.

\footnotetext{
${ }^{1}$ Versión escrita y ampliada de la ponencia en el Seminari Internacional Taula d'Història - El valor social i educativo de la història, organizado por Joaquín Prats $<$ http://www.ub.es/histodidactica $>$ y el Departament de Didàctica de les Ciències Socials. Universitat de Barcelona, 9 de julio de 2007.
} 
Las propuestas y reflexiones que hoy ponemos a debate sobre el qué, el cómo y el por qué de la enseñanza de la historia en el nuevo siglo, responden a un doble interés: 1) poner en valor, didácticamente, algunos de los consensos sobre la escritura de la historia ya establecidos en el Manifiesto de Historia a Debate de 2001;2) $)^{2}$ recoger, en el contexto del nuevo paradigma historiográfico que defendemos, debates y aportaciones recientes de la metodología didáctica y la epistemología pedagógica, donde se está forzando "desde arriba" la formación de un new paradigm educativo, convergente en unos aspectos pero divergente en otros que son esenciales, con lo que estamos defendiendo para la escritura de la historia y las proposiciones didácticas y pedagógicas que vienen a continuación.

Nuestro objetivo es contribuir desde el oficio de historiador a la actualización de la didáctica de nuestra disciplina, tarea que nos compete también como profesores de una universidad cada vez más implicada, y más presionada a implicarse, en la innovación docente. Queremos también avanzar elementos para la incorporación de un nuevo punto de consenso, sobre la enseñanza de la historia, en el Manifiesto de nuestra red historiográfica, con el fin de completar el ciclo de la investigación e implementación social del conocimiento histórico, cuya falta de continuidad es uno de los problemas agudos que han de resolver los nuevos paradigmas de la historia investigada y enseñada.

\section{The new paradigm}

El origen de buena parte de las "novedades" didáctico-pedagógicas actuales está, aun que no siempre se diga claramente, en el New paradigm in education difundido ampliamente desde los EE.UU. en el mundo anglosajón, en el contexto doble de aprendizaje laboral basado en competencias ${ }^{3}$ y posmodernismo académico, con aportaciones útiles y graves defectos de fondo y forma. Este new paradigm ha tenido una explícita acogida en sectores de la academia la-

\footnotetext{
${ }^{2}$ Hicimos una primera aproximación en La nueva historiografía y la enseñanza de la historia, videoconferencia (20/9/2002) para la Maestría en Educación de la Universidad Virtual de Monterrey, México < video y trascripción disponibles en http://www.h-debate.com/videos/videos/ mexico.htm>; versión en italiano, "La nuova storiografia e l'insegnamento della storia", Storia

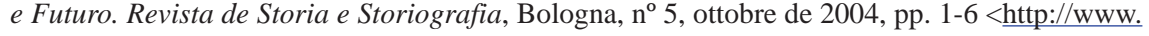
storiaefuturo.com/pdf/59.pdf>.

${ }^{3}$ El origen del concepto de competencias educativas está en el artículo del psicólogo cognitivo norteamericano, especialista en gestión empresarial, MCCLELLAND, David, Testing for competence rather than for intelligence. American Psychologist, n 28, 1973, p. 1-14.
} 
tinoamericana, y otra más implícita de orden administrativo en Europa, como muestra el polémico e importante proyecto para la enseñanza superior Tuning educational structures in Europe ${ }^{4}$ y la "recomendación" categórica de la Unión Europea a favor de la educación por competencias, ${ }^{5}$ especialmente en la educación secundaria. Urge a ambos lados del Atlántico entrar en el debate sobre el consenso teórico-metodológico en marcha, con apoyo institucional, sobre la enseñanza en el siglo XXI, que tome en consideración los sucesivos intentos a lo largo del siglo XX, desde John Deway a Paulo Freire, de una "nueva escuela", a la cual debemos los profesores no seguir aún enseñando con la regla en la mano la lista de los reyes godos. Prolongadas e intensas experiencias de renovación pedagógica, difundidas y aplicadas sobre todo en los años 60 y 70, suelen ser "olvidadas" glosajón, cuando no "apropiadas" en su vertiente constructivista, previamente expurgada de lo que pueda tener de compromiso ético y epistemología social. Dimensiones estas, próximas en su momento al materialismo histórico, que siguen siendo hoy necesarias, en otro contexto y con otros contenidos, en todo nuevo paradigma que se precie, si se quiere hacer frente con éxito al rampante

\footnotetext{
${ }^{4}$ Proyecto financiado por la Comisión Europea, en el marco del programa Erasmus-Sócrates, coordinado por profesores de las universidades de Deusto y Groningen, cara a la convergencia en el Espacio Europeo de Educación Superior; véanse las conclusiones de la Comisión de Historia en http://www.relint.deusto.es/TUNINGProject/spanish/doc2_fase1.asp.

${ }^{5}$ El Parlamento y el Consejo europeos hizeran una "recomendación" el 18 de diciembre de 2006 sobre las ocho "competencias básicas para el aprendizaje", elaborado por la Comisión Europea el 10 de noviembre de 2005 <europa.eu.int/eur-lex/lex/LexUriServ/site/es/com/2005/ com2005_0548es01.pdf>, que el Gobierno español puso en práctica en la Ley Orgánica de Educación (LOE) que entra en vigor este curso 2007/2008, competencias motivadas ante todo por la educación para el empleo, y también espíritu empresarial, formación para la vida y el ejercicio de la ciudadanía; visión crítica en PAGÈS, Joan. Un itinerario por el mundo de las competencias en ciencias sociales, geografía e historia a través de los distintos currículos. Iber. Didáctica de las Ciencias Sociales, Geografía e Historia, nº 52, 2007, p. 29-39.

${ }^{6}$ Por ejemplo, AGUERRONDO, Inés. Un nuevo paradigma de la educación para el siglo XXI. Reformas educativas en Argentina y Canadá. Trama social, gestión y agentes de cambio. Buenos Aires, 2000, <http://www.oei.es/administracion/aguerrondo.htm>; la necesidad de un nuevo paradigma está bien planteada por parte de la autora argentina, pero descalifica como "resabios sesentistas" los cambios del paradigma educativo que vivió el siglo XX, terminando por proponer un doble itinerario, una escuela para ricos y otra para pobres, algo parecido a lo que se propuso sin éxito en España en la segunda legislatura del PP.
} 
retorno ${ }^{7}$ de la escuela conductivista y tradicional, ${ }^{8}$ de un lado, y a los retos de la sociedad de la información, ${ }^{9}$ la globalización y las nuevas tecnologías.

\section{Alianza didáctica / historiografía}

Ivo Matozzi organizó, en la universidad de Bologna, los días 19-20 de octubre de 2004, un congreso internacional en base a la siguiente cuestión: Storiografia e insegnamento della storia: è possibile una nuova alleanza? Desde luego, respondimos algunos, invitados a hablar sobre el nuevo paradigma de la historia y su relación con su enseñanza. ${ }^{10}$ La superación de la crisis de la historiografía, de la historia enseñada y del aprendizaje de la historia, ${ }^{11}$ ha de superarse necesariamente de forma conexa. De mismo modo que, en los años 60 y 70, la eclosión de la nueva historia y la nueva didáctica fueron fenómenos paralelos e conectados entre sí, en el marco del florecimiento de las ciencias humanas y sociales. Lo que son hoy nuestras disciplinas, en cuanto a investigación y licenciaturas, ¿no se lo debemos acaso a las grandes escuelas innovadoras del siglo XX, vinculadas a los movimientos sociales, políticos y culturales, que fueron alcanzando su apogeo después de la II Guerra Mundial? Escuelas y movimientos que entraron ciertamente en crisis, a fines de los años 70 , y fueron después rebasados por los profundos cambios históricos, a los que non estuvieron ajenas las ciencias sociales, que precedieron y siguieron a la caída

\footnotetext{
${ }^{7}$ Ejemplo de denuncia es el Manifiesto (2001) de los profesores de Geografía e Historia de la Comunidad Valenciana contra la vuelta al currículo decimonónico, cronológico e historicista, promovido por la contrarreforma escolar de 2000 (cuya aplicación fue suspendida por el Partido Socialista Obrero Español en 2004, y sustituida por la actual LOE), véase en www.ub.es/geocrit/ b3w-283.htm.

${ }^{8}$ En principio, el adversario común de todos los partidarios de un nuevo paradigma es la enseñanza autoritaria de la historia de tipo memorístico, cronológico, acontecimental, centrada en "grandes figuras" al servicio exclusivo del Estado-nación.

${ }^{9}$ Considerar como la Unión Europea que el eje central de la adaptación de la educación a la sociedad del conocimiento son las competencias laborales y empresariales <europa.eu.int/eur-lex/ lex/LexUriServ/site/es/com/2005/com2005_0548es01.pdf>, es un craso error - también para el proyecto europeo - que indica, entre otras cosas, lo lejos que están aún las instituciones europeas (Comisión, Consejo y Parlamento) de la sociedad civil, a causa de su limitada visión neoliberal del proceso de globalización, cuando menos en su proyección educativa.

${ }^{10}$ Nuovi paradigmi della ricerca storica. Storiografia e insegnamento della storia: è possibile una nuova alleanza? Bologna, 20 de octubre de 2004 <audio disponible en http://www.h-debate.com/ Spanish/presentaciones/lugares/bologna.htm>.

${ }^{11}$ MATTOZZI, Ivo. Le ragioni di un convegno internazionale, disponible en http://www.storiairreer. it/IRRE/materiali/PresentazioneStoriografia04.rtf.
} 
del muro de Berlín. Ahora bien, malo vendrá que bueno me hará: dos décadas después del aprovechado y desmentido vaticinio del "final de la historia", ${ }^{12}$ el subsiguiente regreso de las viejas escuelas positivistas en historia, pedagogía y otras ciencias humanas, y la incapacidad reconstructora del posmodernismo, nos obligan a reevaluar y recuperar de forma crítica, y autocrítica, la experiencia de las vanguardias del pasado siglo.

El nuevo paradigma historiográfico que propugnamos ${ }^{13}$ precisa interactuar con la nueva didáctica de la historia porque es el signo (global) de los tiempos, apoyándose en los conceptos de paradigma, comunidad de especialistas y revolución científica (cambio de paradigmas) elaborados por la historiografía pospositivista de la ciencia. ${ }^{14}$ Sin renunciar, ni la educación ni la historia, a sus definiciones científicas, nacidas hace más un siglo y precisadas por lo tanto de una severa actualización de sus epistemológicas de referencia, si queremos que la sinergia que proponemos sea efectiva.

De todos modos, lo que más comparten la historia y la didáctica de la historia es, obviamente, la temática y la noción de historia. En realidad, la investigación y la enseñanza son, o deberían ser, fases consecutivas e interrelacionadas de un mismo proceso de conocimiento histórico. No obstante, hasta hoy la educación histórica e historiográfica de nuevos profesores e investigadores (enseñanza superior) y de nuevos ciudadanos (enseñanzas medias) no ha recibido la misma consideración académica o pública que la historia como investigación.

La docencia es, se quiera o no, una parte cardinal del proceso de conocer la historia, salvo que se niegue su carácter social, reduciendo el saber histórico a la pura erudición. La enseñanza de la historia, y sus comunidades de aprendizaje, es una actividad creativa y difícil que condiciona, y retroalimenta, la fase investigadora del proceso de reconstrucción del pasado. Interconexiones

\footnotetext{
${ }^{12}$ SANMARTÍN, Israel, The end of History looking back and thinking ahead. In: BARROS, Carlos and MCCRANK, Lawrence J. (eds.) History under debate. International reflection on the discipline. New York, 2000, p. 253-259.

${ }^{13}$ No estamos de acuerdo con los que, ejerciendo la justa y necesaria crítica del condicionamiento de la reforma educativa europea por los intereses empresariales, renuncian a ofrecer nuevas alternativas, ignorando la historia de la renovación pedagógica y metiendo en el mismo saco todo lo que suene a "nuevo paradigma educativo", e-learning, aprender habilidades o formación continua, v.g. GARCÍA FERNÁNDEZ, Jorge Felipe. Algunas consideraciones acerca del proyecto Tuning educational structures in Europe. Madri: Universidad Complutense < $\underline{\text { http://firgoa.usc.es/drupal/ }}$ node/25877>.

${ }^{14}$ Véase El paradigma común de los historiadores del siglo XX. Medievalismo. Madrid, nº 7, 1997, p. 235-262 <http://www.h-debate.com/cbarros/spanish/paradigma_comun.htm>.
} 
disciplinares y funcionales que todavía no (re) conocemos bien: faltan investigaciones mixtas ${ }^{15}$ que relacionen historia investigada e historia enseñada desde un punto de vista tipo temático, metodológico, histórico e historiográfico. Tenemos, pues, que aplicar la interdisciplinariedad a nuestra propia disciplina, estableciendo puentes entre sus diversos segmentos, inscritos a menudo en otros campos académicos, ${ }^{16}$ practicando una suerte de intradisciplinariedad ${ }^{17}$ que haga rentable la cooperación de la historia con otras ciencias sociales, ${ }^{18}$ ciencias de la educación, en el caso que nos ocupa.

Este tipo de alianza académica entre la historia y la didáctica de la historia, entre la investigación y la enseñanza, es aplicable como índice de calidad en cualquier otra materia de estudio. El neoconstructivismo anglosajón no promueve, sin embargo, estas interdisciplinariedades cercanas. Las ciencias de la educación pasaron de inspirarse en la psicología, primero conductista, después cognitiva, a seguir los códigos pedagógicos del mundo de la empresa, extraídos de una rama del cognitivismo, ${ }^{19}$ asumiendo como principio rector de cualquier aprendizaje la adquisición de competencias. Planteado de manera fundamentalista esta versión del nuevo paradigma orientada al mercado laboral, cualquiera que sea la temática docente, obstaculiza la búsqueda de cierta coherencia entre la investigación y la docencia, los contenidos y los métodos de aprendizaje, cuestión capital en aquellas disciplinas - como la historia - más alejadas de los estudios laborales, técnicos y empresariales (business school).

Desde las comunidades académicas vecinas debemos apostar por convergencias transversales que sirvan de contrapunto a aquellas directrices tecnocráticas y economicistas que puedan lesionar el presente y el futuro de nuestra disciplina

\footnotetext{
${ }^{15}$ Véase La historia mixta como historia global, disponible en http://www.h-debate.com/cbarros/ spanish/articulos/historia_medieval/mixta.htm.

${ }^{16}$ La pertenencia de un investigador a dos comunidades académicas distintas enriquece a ambas, debería ser una práctica habitual y lo será en la medida en que superemos el gremialismo que genera la fragmentación académica, especialmente arraigado en España, todo hay que decirlo.

${ }^{17}$ Punto IV del Manifiesto historiográfico de Historia a Debate, disponible en portugués del Brasil en http://www.h-debate.com/Spanish/manifiesto/manifiesto had.htm.

${ }^{18}$ De intradisciplinariedad para superar el conocimiento histórico fraccionado poco o nada se dice en el proyecto Tuning, cuyas querencias posmodernas se manifiestan de nuevo al proponer la crítica literaria, y la historia del lenguaje, como la primera habilidad que los alumnos universitarios de historia han de importar de "otras ciencias humanas" por delante de otras ramas de la historia, de la sociología o de la antropología, véase el Anexo 2 del documento de la Comisión de Historia. Puntos comunes de referencia para los cursos y currículos de Historia, disponible en http://www. relint.deusto.es/TUNINGProject/spanish/doc2_fase1.asp.

${ }^{19}$ Véase la referencia de la nota 3.
} 
histórica, y de la educación en general. Es menester, a tal fin, superar prejuicios y suspicacias existentes entre historiadores y "didactas", docentes universitarios y docentes medios etc., fruto de evoluciones separadas en el ámbito disciplinar e institucional, pese a una formación inicial común en historia que toca potenciar, sobrepasando la noción tradicional de la comunidad académica de historiadores y profesores de historia, como algo restringida a los investigadores y docentes vinculados a las licenciaturas universitarias de historia.

Estamos planteando por lo tanto una coalición entre iguales, lo que resulta en general más hacedero entre profesores universitarios, aun perteneciendo a áreas, licenciaturas y departamentos distintos, que con los colegas de enseñanzas medias, ${ }^{20}$ pese a ser los más implicados en la problemática didáctica, por obligación y vocación (menos frecuente en la enseñanza superior). Relaciones, por lo tanto, horizontales e bilaterales tanto académica como epistemológicamente. No se trata de aplicar, sin más, como en los años 60 y 70, un "modelo historiográfico" surgido de la reflexión o la investigación histórica a la enseñanza como de intercambiar avances y dificultades en un proceso conjunto (sujeto a debate permanente) de reconstrucción de un nuevo paradigma que busque relacionar la historia con su enseñanza. ${ }^{21}$ Todos escribimos, enseñamos y divulgamos la historia, en diferentes dosis, enfoques y estilos. Entendemos la historia como una "ciencia con sujeto": ${ }^{22}$ social (agentes del pasado y del presente), historiográfico (historiadores) y docente (profesores). El principal sujeto docente de la historia está, sin duda, en la educación secundaria: hay que incluir al profesorado medio en la comunidad de historiadores por medio de aquellos sectores más vinculados a la innovación docente, la reflexión historiográfica y/o la investigación histórica, como ya está ocurriendo en la red temática Historia a Debate.

\footnotetext{
${ }^{20}$ Véase la conclusión $n^{\circ} 8$ del III Congreso de la red temática Historia a Debate sobre la urgencia de "ampliar la comunidad académica de historiadores a la investigación y la enseñanza de la historia no universitaria" disponible en www.h-debate.com/cbarros/spanish/articulos/nuevo_paradigma/ conclusiones 3had/primeras\%20conclusiones.htm.

${ }^{21}$ En nuestra intervención boloñesa (véase la nota 10 ) preconizamos lugares de encuentro, debate y consenso, como Historia a Debate y este Taula de la Història en que estamos, más allá de la especialidad y del estatus académico, demandando de los docentes medios la función de mediadores entre la sociedad civil y la historiografía, pero también opiniones críticas y alternativas sobre la historia que se debe investigar en la universidad, y sus enfoques. El nuevo paradigma del la investigación histórica. Storiografia e insegnamento della storia: è possibile una nuova alleanza? $<$ http://www.h-debate.com/Spanish/presentaciones/lugares/bologna.htm>.

${ }^{22}$ Punto I del Manifiesto historiográfico de Historia a Debate.
} 
Ahora bien, abarcar de manera concurrente la investigación y la docencia, las enseñanzas superior y media, entraña considerar también sus diferencias: (1) la mayor cercanía del sujeto docente a la ciudadanía, especialmente en la enseñanza secundaria; $y$, en consecuencia, (2) un mayor control administrativo del conocimiento histórico que se enseña y de su metodología de aprendizaje. ${ }^{23}$ A diferencia de la investigación histórica, ${ }^{24}$ el contenido de los planes de estudio de las asignaturas de historia, y su didáctica, están por razones políticas y culturales determinadas por ley en la enseñanza secundaria, y en menor medida en la enseñanza superior. ${ }^{25}$ Es por ello que la alianza historia investigada / historia enseñada que planteamos, en el marco de los nuevos paradigmas en construcción, tanto en historia como en educación, habría de permitir una mayor autonomía de la sociedad académica frente a la sociedad política y sus intereses, no siempre eficientes y a veces no coincidentes además con las mayorías sociales y el futuro de la historia. Movilización y convergencia académica inter e intradisciplinar que ha de situar asimismo entre sus objetivos, una participación más transparente y democrática del profesorado en la toma pública de decisiones que afectan a nuestro trabajo y función social.

\section{El papel público de la historia}

La transición histórica, global y civilizatoria, que estamos viviendo coloca a la historia profesional en una tesitura paradójica por razones externas (cambios

\footnotetext{
${ }^{23}$ Por su dimensión política, son más conocidas las batallas por los contenidos de la historia que se enseña, pero non son menos importantes las relativas a la forma de enseñar, donde también se implica para bien y para mal la administración, sobre todo en la educación obligatoria; no hay más que ver la rapidez con que el Gobierno de España aplicó a la LOE la educación por competencias "recomendada" por la Unión Europea, y la libertad que van a tener los Estados para decidir contenidos y competencias en el proceso de convergencia de la enseñanza universitaria (véanse las notas 5 y 25).

${ }^{24}$ La investigación en la universidad está más sujeta a la libertad de cátedra, si bien resulta eficazmente condicionada, por la vía de las subvenciones, por una radical discriminación (ante todo en la Unión Europea) entre líneas prioritarias y no prioritarias (donde suele estar la historia), y por un anticuado sistema de evaluación de proyectos (no sólo España) que contradice, con harta frecuencia, los criterios legales de objetividad e impulso de la investigación innovadora (no sólo en Historia). ${ }^{25}$ La Comisión de Historia del proyecto europeo Tunning deja en manos de los Estados miembros lo fundamental de los currícula universitarios, reduciendo al mínimo las consideraciones comunes de tipo general (véase la nota 80 ), con lo que se va a perder una buena ocasión, entre otras cosas, de enseñar históricamente a los ciudadanos de Europa el carácter plural de la identidades colectivas, algo vital para que se desarrolle una identidad europea (véase también nota 108) por encima de los Estados-nación que seguirán naturalmente centrando los planes de estudio en sus historias nacionales.
} 
en la conexión historia-sociedad) e internas (crisis de paradigmas), íntimamente relacionadas, de forma que la prolongación de lo segundo obstaculiza que la historia académica lleve la iniciativa cara a la sociedad, en temas que le son propios, lo que si se hizo en la transición del siglo XIX al siglo XX, y posteriormente en los cruciales años 60 y $70 .{ }^{26}$

La aceleración de la historia que siguió a los cambios 1989-1991 en la Europa del Este, dando al traste con el "fin de la historia" proclamando oportunamente por los neocons norteamericanos, produjo un "retorno de la historia"27 con dos rasgos complementarios y sólo aparentemente contradictorios: auge de los "usos públicos de la historia" y, simultáneamente, el regreso al positivismo decimonónico de una parte de la academia historiográfica, lo que agudiza el corporativismo de los historiadores, aislando a nuestra disciplina y entorpeciendo que pueda responder, adecuadamente, a las nuevas demandas históricas e historiográficas de la sociedad.

Como es sabido, el interés político por la historia es propio de las coyunturas de grandes cambios, resultando acrecentado en este momento por la dimensión global de las mutaciones, en su doble sentido de mundial y total (afecta a todos los ámbitos de la vida), transformando a los medios de comunicación y edición en nuevos sujetos políticos de la historia, junto con las viejas instituciones y los viejos y nuevos movimientos sociales. La reacción de las comunidades de historiadores, ante este retorno público de la historia, tiene su complejidad: 1) aprovechamiento individual - aunque minoritario - de las nuevas oportunidades de publicación y presencia en los medios, subvenciones, premios etc.; previa adaptación en ocasiones a los gustos historiográficos de instituciones y mercados político-culturales; 2) rechazo puntual y gremial de la intromisión de los agentes políticos, económicos y sociales en el "terreno" de los historiadores, que empuja a historiadores de oficio hacia las añejas creencias positivistas de que "la historia es conocer el pasado tal como fue" (Ranke) o que "la historia se hace con documentos" (Langlois y Seignobos), que imaginábamos (está claro que erróneamente) superadas gracias a la escuela de Annales y la historiografía

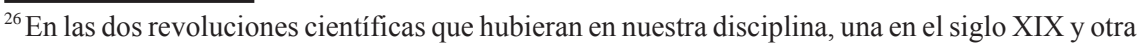
en el siglo XX, nos beneficiamos de la existencia de unos paradigmas ilustrados que encuadraban las ciencias sociales, el positivismo y el marxismo, pero la transición del silgo XX al siglo XXI todavía no ha generado algo parecido.

${ }^{27}$ El retorno de la historia. Historia a debate. I. Cambio de siglo. Santiago, 2000, p. 153-173 <www.h-debate.com/cbarros/spanish/articulos/nuevo_paradigma/retornohistoria.htm>.
} 
marxista; 3) aprovechamiento colectivo del interés renovado por la historia y los nuevos medios para crear nuevas experiencias y tendencias historiográficas que respondan a las necesidades históricas actuales de tipo cultural, social y político, es el caso de corrientes como Historia a Debate, la "idea histórica de España" y la recuperación de la memoria histórica, ${ }^{28} \mathrm{o}$ las norteamericanas Public History ${ }^{29}$ y Historians against the War. ${ }^{30}$

Peligroso reduccionismo de la historia profesional a la empiria que deja terreno libre, al presente, a los poderes interesados en escribir la historia pasada, presente y futura, pretendiendo reubicar a los historiadores como simples técnicos especialistas en archivos y fuentes, académicos enclaustrados, proveedores de datos históricos pero no pensadores de la historia, lo que correspondería en determinados temas a políticos y otros productores de ideología. Aceptar esta “división del trabajo" es el mayor error que la historia investigada y enseñada puede cometer, ¿cómo vamos a enseñar a los alumnos a "pensar la historia" si nosotros no lo practicamos? Cuando se dice que "la historia hay que dejarla a los historiadores", se nos está ofreciendo un regalo envenenado, porque tal cosa no es posible ${ }^{31}$ ni deseable, ${ }^{32}$ suele esgrimirse además para encubrir segundas intenciones. ${ }^{33}$ Recordemos que el supuesto monopolio del historiador académico sobre la historia escrita, su neutralidad per se y la no interferencia, se planteó en el siglo XIX cuando los historiadores están fundamentalmente comprometidos con los grandes proyectos nacionales, empezando por el fundador el positivismo historiográfico, Leopold von Ranke. Pero en el último siglo la historiografía se ha hecho más autónoma, crítica y plural, también en sus relaciones con la sociedad y las instituciones, ¿a quién le puede beneficiar una marcha atrás?

\footnotetext{
${ }^{28}$ Véase la conclusión $n^{\circ} 6$ del III Congreso de la red temática Historia a Debate sobre "el dinamismo y la autonomía de la historiografía española en la última década", disponible en www.hdebate.com/cbarros/spanish/articulos/nuevo_paradigma/conclusiones 3had/primeras $\% 20$ conclusiones.htm.

${ }^{29}$ Véase la nota 35 .

${ }^{30}$ Más información en http://www.historiansagainstwar.org.

${ }^{31}$ Cuando una cuestión histórica está de actualidad, sobran sujetos no académicos que quieren intervenir en su interpretación y escritura, cuando no llevar la iniciativa de su puesta en valor, como en el caso citado de la "idea histórica de España" entre 1996 y 2004.

${ }^{32} \mathrm{El}$ presentismo de la sociedad de la información hace que el futuro de la historia dependa más que nunca de su presente utilidad social y política.

${ }^{33}$ Lo de que "hay que dejar la historia a los historiadores" ha sido un argumento repetido para rebajar o impedir, en el Parlamento español, una inconclusa "ley de memoria histórica", que tendría por finalidad restablecer la dignidad de los republicanos desaparecidos en la guerra civil y su causa democrática, el antecedente más reciente de la democracia actual.
} 
Sin renunciar al rigor y la honestidad en el uso de las fuentes que distingue el historiador de oficio, el interés de la historia como disciplina ${ }^{34}$ debería incentivarnos a tomar más la iniciativa de su uso público ${ }^{35}$ cuando las circunstancias, el tema o el enfoque lo requieran, en competencia con otros cultivadores de la historia. Aceptamos como una bendición para nuestra disciplina el renovado gusto público por el pasado, ${ }^{36}$ mejor dicho, por determinados aspectos y enfoques del pasado, desde diversos y a veces contrapuestos medios políticos e institucionales, mediáticos y sociales, independientemente de las motivaciones y el grado de rigor - o de mitificación - de dichos acercamientos. Abandonando actitudes que puede sentirse como prepotentes, sin dejar de lado las aportaciones extra-académicas sobre la historia que nos han de enseñar mucho sobre la relación del historiador y su contexto, la recepción actual de los hechos pasados, la interacción cambiante entre pasado y presente, pasado y futuro, lo que hace de la historia algo vivo, en suma. Sin historiadores en la arena pública, ${ }^{37}$ la alternativa será la banalización de la historia como un producto más del debate ideológico y la sociedad de consumo. ${ }^{38}$

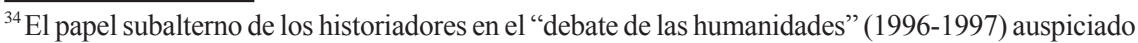
por el primer Gobierno del Partido Popular, explica también que el interés público en favor de la historia, y otras humanidades, no supusiera finalmente más horas y profesores de historia en los institutos ni más medios para la investigación de la historia en las universidades.

${ }^{35}$ En la academia norteamericana se ha desarrollado, desde los años 80, una public history $<\underline{\text { http:// }}$ www.ncph.org/index.html > entendida como historia aplicada a una audiencia no académica, dedicada a la gestión y difusión del patrimonio y de la memoria colectiva, la difusión del conocimiento histórico a través de TV y medios digitales, trabajando desde instituciones académicas y no académicas (universidades, archivos, museos, asociaciones, instituciones culturales y políticas, media), promoviendo la responsabilidad pública de los historiadores y abriendo nuevas salidas profesionales para los licenciados; lo mejor de este planteamiento historiográfico es su carácter colectivo y el énfasis que pone en hacer accesible la información histórica al público en general; se trata de actividades que se hacen asimismo entre nosotros pero no tienen, desde luego, el mismo grado de coordinación y valoración, dentro y fuera de la universidad; echamos de menos, en cualquier caso, en esta nueva corriente historiográfica anglosajona referencias claras sobre: 1) los valores historiográficos, éticos y públicos que guían la public history; 2) las consecuencias teóricas que implica para la redefinición de lo qué es un historiador, esta (positiva) ampliación del oficio que parecen proponer los historian public; 3) las relaciones historia académica / historia pública, entre los que investigan la historia y los que aplican, gestionan y difunden la historia, entre la historia y la política de la historia, en suma.

${ }^{36} \mathrm{El}$ apogeo en España de las revistas de divulgación histórica, con un nivel aceptable y alta difusión, es otro síntoma del "retorno de la historia" y también consecuencia del peso público de las últimas tendencias vinculadas a los actores políticos-sociales, especialmente la "idea histórica de España". ${ }^{37}$ Lo que implica cambios de actitud e sensibilidad, incluso de forma de escribir la historia, no siempre fáciles para un historiador de formación exclusivamente académica y especializada.

${ }^{38}$ Ya está sucediendo, véase si no el bajísimo nivel historiográfico de los libros de historia que
} 
El elemento decisivo del espacio público de la historia, son las escuelas: en ningún otro lugar es más conveniente que el profesor de historia actúe como un historiador público, comprometido con la tarea de hacer de los alumnos parte activa del sujeto de la historia que se aprende y que se hace. Para ello es preciso reclamar motu propio el carácter público de la historia que investigamos y enseñamos en las instituciones públicas del Estado. Hacemos nuestra la reivindicación del "valor social y educativo del conocimiento histórico" del Manifiesto del Seminario Internacional de Didáctica de la Historia (Barcelona, 10/7/2007), ${ }^{39}$ y la demanda primordial de que la "historia sea una materia que ocupe un lugar importante en el currículum educativo general, desde el inicio de la educación primaria hasta la universidad”. Materia histórica que, a su vez, si queremos predicar con el ejemplo, ha de ser consecuencia de una historiografía y una pedagogía, de una investigación y una difusión de la historia basada en valores universales de "justicia e igualdad, paz y democracia", ${ }^{40}$ lo que nos obliga a salir de los cuarteles académicos de invierno, debatir y, cuando sea preciso, tomar partido.

\section{El disputado papel del profesor}

Ni tanto ni tan poco: ni el profesor autoritario de la escuela tradicional, vinculado a la enseñanza de la historia basada en la memorización de grandes nombres, fechas y batallas, "clases magistrales" y alumnos pasivos; ni el profesor como el simple facilitador ${ }^{41}$ y coordinador del autoaprendizaje de los alumnos de la escuela posmoderna, que proclama el "todo vale" en cuanto a historia enseñada, incluyendo el contenido corrientemente tradicional ${ }^{42}$ de la historia oficial correspondiente. Sostenemos que el papel activo del alumno es complementario

\footnotetext{
tratan de reivindicar, 80 años después, la interpretación franquista de la II República y la guerra civil españolas.

${ }^{39}$ Véase http://www.taulahistoria.org/castellano/.

${ }^{40}$ Véase el punto XVI sobre la actualización del concepto "compromiso del historiador" en el Manifiesto historiográfico de Historia a Debate.

${ }^{41}$ En Estados Unidos y América Latina, existe abundante bibliografía y recursos en Internet sobre el facilitator como figura esencial del new management, también en el sistema educativo, con sus pautas de comportamiento "neutro" etc., es considerada una nueva profesión y existe una asociación internacional desde 1994.

${ }^{42}$ Una forma reciente de tradicionalismo educativo es el "enciclopedismo", una inflación de la materia docente que, pretendiendo abarcar, por ejemplo, "toda la historia de España", no deja tiempo para las innovaciones docentes (ni para la historia inmediata), véase el Manifiesto de los profesores valencianos de 2001 (nota 7).
} 
con la función docente y social del profesor, ${ }^{43}$ pero no puede reemplazarla, como se pretende, ni siquiera con la valiosa ayuda de la red. Alumnos y maestros activos, y comprometidos, son unos y otros imprescindibles, al mismo tiempo, si lo que se quiere son unas comunidades de aprendizaje realmente inteligentes. ${ }^{44}$ Rebajar el profesor de historia a monitor de clases prácticas, testigo mudo sobre todo de aquello que implique interpretación, ${ }^{45}$ tiene sus consecuencias perversas: abrir la puerta a un mayor control administrativo de una materia tan esencial para formación de los ciudadanos, ${ }^{46}$ no se trata de una propuesta políticamente inocente. ${ }^{47}$ Aunque lo peor es que la "comunidad de aprendizaje" entendida a la moda anarco-conservadora conduce a un fracaso pedagógico ${ }^{48}$ que beneficia a las tendencias restauradoras de la escuela autoritaria. ${ }^{49}$

Otra cosa es reubicar el papel del profesor en un contexto de mayor actividad del alumno, donde aprende por su propia experiencia y el debate colectivo, rol que variará según el formato de cada actividad: trabajos colectivos y prácticos, clases teóricas, tutorías etc. Una cosa está clara, las lecciones, y por lo tanto el

\footnotetext{
${ }^{43}$ El realce del valor social y educativo de la historia que reivindicábamos en el apartado anterior del texto pasa necesariamente por la potenciación y dignificación social, educativa y laboral de los profesores de historia.

${ }^{44}$ Según el Diccionario de la Real Academia Española, "inteligencia” es "capacidad de comprender, conocimiento, capacidad de resolver problemas, habilidad, destreza, experiencia..."; atributos que exigen un sistema docente participativo pero articulado por profesores activos: es una perogrullada pero hay que decirlo.

${ }^{45}$ En febrero de 2005 participamos en el I Encuentro Internacional sobre la docencia de la historia en el bachillerato, organizado por la Secretaria de Docencia de la Universidad Autónoma del Estado de México; en una sugerente simulación de un "aula inteligente" - constructivista, según las normas - formada por los propios maestros, los coordinadores entendían que debían solamente organizar la mesa, facilitar las intervenciones de los que hacían de alumnos y guardarse su opinión.

${ }^{46}$ PAGÈS, Joan, Un itinerario por el mundo de las competencias en ciencias sociales, geografía e historia a través de los distintos currículos, p. 30.

${ }^{47}$ El perfil de los profesores de historia, en institutos de enseñanza media (y de titularidad pública, en las privadas no suele haber historia, salvo las creadas por los jesuitas), es y sigue siendo mayoritariamente progresista, como todos sabemos, con lo que la minusvaloración "desde arriba" del papel del profesor tiene una indudable dimensión político-ideológica.

${ }^{48}$ La resistencia del profesor a una educación por competencias, impuesta administrativamente, se puede agrandar con las propuestas excesivas, faltas de realismo y espíritu de síntesis, convirtiendo en papel mojado las "nuevas directrices", pasó algo así con reformas anteriores.

${ }^{49}$ Del mismo modo que volvió, en los años 80 , la cronología después del "fracaso" de la enseñanza estructuralista de la historia, cada vez encontramos más en los planes de estudio una historia narrativa de "grandes acontecimientos" y "grandes figuras", al tiempo que se alzan voces conservadoras a favor del regreso del profesor-rey: la propuesta Nicolas Sarkozy, durante su campaña electoral para la Presidencia de Francia, de que los alumnos se levanten cuando el profesor entra en el aula, entre otras lindezas, es todo un signo.
} 
programar formal, han de ocupar menos tiempo para dejar espacio para las actividades colaborativas de los alumnos, donde aprenden a aprender, distribuyendo la temática (necesariamente selectiva) entre ambos tipos de actividad docente.

Veremos en el próximo apartado, con todo, como este papel activo de los alumnos ha sido preocupación común de todos los movimientos de renovación didáctica-pedagógica que nos han precedido. La obtención de resultados colectivos exige la acción del profesor, en todo momento, y la predisposición y motivación de los alumnos, condicionados ambos por la tradición pedagógica de cada nivel educativo, institución y país. En la encuesta ${ }^{50}$ hecha acerca del proceso de Bolonia, se hallaron dos modelos didácticos, el latino (Francia, España) y el anglosajón (Inglaterra, Irlanda), sobre los que giran el resto, inclinándose Italia y Alemania hacia el eje latino. En el caso inglés, se exige a los estudiantes que se organizen en "grupos autónomos de investigación en los que ellos mismos deben definir sus temas, encontrar los materiales necesarios para abordarlos y preparar informes", mientras que en la Europa sureña el interés profesoral se concentra en definir los contenidos de las asignaturas, ${ }^{51}$ con cierto desinterés por la metodología docente, lo que muestra la pervivencia del sistema tradicional de contenidos transmitidos por el profesor y el estudio por el manual, que resulta reforzado por oposición si la alternativa es el profesor como facilitador.

En esto como en tantas cosas, el paradigma educativo es realmente nuevo si encuentra una síntesis ${ }^{52}$ que haga posible el consenso, impulsando a la vez el papel de los alumnos y del profesor, lo que se concreta en la necesidad de combinar inteligentemente: saberes y competencias en los currículos y la práctica docente, por un lado; competencias y valores, por el otro. No es esto lo que persiguen las directrices administrativas de influencia anglosajona, ${ }^{53}$ que propagan la OCDE y la Unión Europea, cuando hablan de pasar del profesor al facilitador, de los conocimientos a las competencias, tratando ambos conceptos

\footnotetext{
${ }^{50}$ Proyecto Tuning. Grupo del área temática de Historia. Puntos comunes de referencia para los cursos y currículos de Historia, p. 171< http://www.relint.deusto.es/TUNINGProject/spanish/ doc2 fase1.asp>.

${ }^{51}$ De ahí el exceso enciclopedista que comentábamos en la nota 42.

${ }^{52}$ Todavía se confunde síntesis con eclecticismo o, lo que es peor, con "tercera vía" o middle point, ignorando que todo es síntesis y nada se produce ex novo.

${ }^{53} \mathrm{El}$ debate sobre el nuevo paradigma educativo es, en buena medida, un debate sobre tradiciones nacionales y geoestratégicas de tipo pedagógico-didáctico, influidas por tradiciones y realidades diversas de tipo filosófico, político e ideológico.
} 
como excluyentes, y restringiendo al mínimo ${ }^{54}$ los valores éticos y profesionales explícitos que han de sustentar la nueva forma de enseñar.

\section{Competencias y tendencias}

No negamos que la idea laboralista ${ }^{55}$ de que la educación ha de dotar a los alumnos, en los diversos niveles de enseñanza, de competencias, habilidades o destrezas, puede suponer un avance didáctico siempre y cuando se articule coherentemente con las propuestas y enfoques del conocimiento a transmitir, y los valores de referencia, lo cual exige una rectificación a fondo de la versión anglosajona, que resuelva las contradicciones de fondo, ${ }^{56}$ de un new paradigm admitido acríticamente por las administraciones, ${ }^{57}$ con la subsiguiente infravaloración, más o menos interesada, de las propias tradiciones renovadoras.

La presión política y económica a favor de una educación por competencias, pensada por sus más altos promotores para adecuar todavía más la universidad (más allá de los estudios económico-empresariales) y las enseñanzas medias (más allá de la formación profesional) al mercado de trabajo ${ }^{58}$ puede coadyuvar paradójicamente al viejo empeño innovador de enseñar críticamente a los alumnos cómo funcionan las cosas, si conjuremos la intencionalidad tecnocrática

\footnotetext{
${ }^{54}$ Atrapados entre las directrices administrativas para imponer en la universidad el "aprendizaje de competencias", a partir de la experiencia inglesa, y el interés - que ellos reconocen como unánime en Europa - sobre "la necesidad de definir las razones éticas y heurísticas para el estudio, aprendizaje y enseñanza de la historia", el Grupo de Historia del proyecto Tuning ha incluido, finalmente, en sus sugerencias y propuestas, como objetivo general del estudio de la historia, "la adquisición de una visión racional y crítica del pasado con el objeto de estar capacitado [el alumno] para comprender [les falta decir 'críticamente'] el presente y para ejercer de forma cabal la ciudadanía”; versión moderada (falta curiosamente lo de "construir el futuro") de las tradiciones histórico-políticas europeas que han engendrado, y difundido por el mundo, la idea del progreso y el concepto de ciudadanía. ${ }^{55} \mathrm{La}$ enseñanza directa para el mercado laboral se ha centrado siempre en capacitar al alumno haciéndole competente en habilidades prácticas para al trabajo manual, administrativo etc.; al pretenderse ahora su generalización a todo tipo de enseñanza, las destrezas manuales y técnicas pasan a ser más intelectuales, conservando un "pecado original" productivista que tiene su parte positiva como el trabajo con fuentes en historia.

${ }^{56}$ Hipermodernista en lo tocante a preparación competencial y eficiente de los futuros trabajadores o emprendedores; posmodernista por dejación de los valores ilustrados y legitimación del "todo vale".

${ }^{57}$ No siempre son administraciones de matiz conservador y neoliberal que saben lo que hacen, muchas veces se trata de seguir la moda, ignorando la filosofía subyacente, la estrechez de miras y los efectos potencialmente perversos de una educación en competencias puras.

${ }^{58}$ Afortunadamente la difusión y aplicación de la implementación de la "educación por competencias" se está dando en un momento en que el fundamentalismo del mercado está de capa caída, ¿será por eso que tiene que soportar la educación pública, vital para nuestro futuro, estos coletazos?
} 
de sesgo neoliberal, contradictoria con los valores universales y deontológicos de una nueva Ilustración global, ${ }^{59}$ destinada en opinión de muchos a orientar la docencia de las ciencias humanas y sociales en el nuevo siglo. De momento la impuesta educación por competencias, y otras innovaciones recientes en metodología docente, son intencionadamente extrañas, señaladamente en la enseñanza media, ${ }^{60}$ a los debates temáticos y organizativos sobre los currículos, dejando por omisión - pero no conscientemente - a las posiciones tradicionales y las autoridades competentes los contenidos de la enseñanza y la distribución del tiempo escolar. ${ }^{61}$

Un ejemplo concreto: las ocho "competencias básicas para el aprendizaje" que según la "recomendación" de la Comisión y el Parlamento europeos han de orientar en lo educativo a los Estados miembros, y que el gobierno español ya introdujo en la Ley Orgánica de Educación (media) que acaba justamente de entrar en vigor en algunas comunidades autónomas: "comunicación en la lengua materna (1); comunicación en lenguas extranjeras (2); competencia matemática y competencias básicas en ciencia y tecnología (3); competencia digital (4); aprender a aprender (5); competencias interpersonales, interculturales y sociales, y competencia cívica (6); espíritu de empresa (7), y expresión cultural (8)". ${ }^{62}$ Nada que objetar como principios psicopedagógicos siempre útiles, si acaso que son un poco vagos de tan generales. El problema es todo lo que excluye (contenidos), oculta (valores mercantiles) y promueve (facilitación) esta entronización de las competencias como panacea educativa.

Algunos contenidos aparecen camuflados como objeto de las competencias (lenguas, matemáticas, tecnología, digital), por razones instrumentales de tipo laboral competitivo; pero nada se dice de "competencias" historiográficas, filosóficas, geográficas o sociológicas, por ejemplo. Los valores ni se mencionan en el núcleo duro de la "recomendación" didáctico-pedagógica, quitando dos casos:

\footnotetext{
${ }^{59}$ ¿Qué sentido tiene la historia como disciplina académica y ciencia social, sin la reconstrucción de la idea de progreso, y por lo tanto de la relación pasado / presente / futuro, en el nuevo contexto de la globalización?

${ }^{60}$ En cambio, el European Credit Transfer System (ECTS) del proceso de Bolonia supone un cambio importante del empleo del tiempo en la Universidad, reduciendo en principio las clases magistrales, falta ver con todo su aplicación.

${ }^{61}$ Es una queja general, y justa, entre los profesores de medias que la longitud enciclopédica de la materia a impartir no deja tiempo para las clases interactivas, el trabajo con fuentes, Internet 0 la historia fuera del aula, véase la nota 42.

${ }^{62}$ Véase el documento completo (10/11/2005) en europa.eu.int/eur-lex/lex/LexUriServ/site/es/ com/2005/com2005 0548es01.pdf, y también la nota 5 .
} 
el "espíritu de empresa", algo nuevo en instituciones públicas como instrucción básica sobre la enseñanza que han de recibir todos los niños y niñas en edad escolar; y la "competencia cívica", a modo de coletilla de las "competencias interpersonales" y planteada más como destreza que como valor democrático, con la idea de asegurar que el alumno/a aprenda en la escuela el sistema político en el que deberá participar de mayor.

Por suerte, la práctica ya está abriendo brechas en el bunker de la ortodoxia educativo-competencial: (1) en la difusión y aplicación de las competencias básicas de la UE, no suelen aparecer alusiones a algo tan descabellado como preparar básicamente a todos los alumnos para ser empresarios; y (2) la "competencia cívica" reconvertida en "educación para la ciudadanía y los derechos humanos", más vinculada a valores que a un pragmatismo político, sabedores como somos que la participación ciudadana es, ante todo, cuestión de derechos y convicciones ético-políticas. Aún así, la reconducción del proceso global de reforma educativa en curso no va a ser fácil ni indolora, y no debería concluir el debate, que recién está en sus comienzos y durará años, hasta que se reemplace el nuevo paradigma de las competencias por el nuevo paradigma de los saberes, los valores y las competencias, donde cada uno de estos tres criterios educativos valga tanto como el otro, combinándose entre ellos en dosis dependientes del tipo de materia a enseñar y sus contextos. Mezcla química que supieron aplicar ya en su tiempo las corrientes renovadoras, complementándose entre sí, en el marco del paradigma común de los profesores del siglo XX.

Precisamos, pues, retomar críticamente los intentos reformadores de la escuela a lo largo del pasado siglo, que fueron capaces de fusionar - o lo intentaron al menos - el método de aprendizaje, con la historia de la didáctica, la teoría pedagógica y la interacción social: primera enseñanza de los años 60-70 que urge evocar. Recuperación de la memoria didáctica y pedagógica que nos obliga a calibrar éxitos, fracasos ${ }^{63}$ y por encima de todo el contexto actual, muy

\footnotetext{
${ }^{63}$ El relativo fracaso de los constructivistas fue tal vez centrarse en la psicología como inspiración y en la metodología como obsesión, relegando el resto; el marxismo pedagógico, cuyas máximas expresiones se dieron en América Latina y la Unión Soviética, resultó afectado por la crisis general del marxismo y la caída del Muro, precisando ahora sus aportes de compromiso y determinación social un desarrollo más complejo y actual; ahora bien, gran parte del fracaso de las reformas educativas, no fueron tanto culpa de las tendencias pedagógicas y/o historiográficas como de las políticas que seleccionaron y aplicaron contenidos y métodos burocráticamente, y así lo juzga la sociedad, incluidos docentes y discentes, y así juzgarán en el futuro.
} 
distinto a 30 o 40 años atrás, marcado por una transición histórica inédita, la revolución de las comunicaciones y demás globalizaciones en marcha.

Las tendencias pedagógicas emergentes de aquellos años lograron, con su convergencia, algo que ahora echamos en falta, y ya comentamos: innovar los métodos y los contenidos a la vez, ${ }^{64}$ la práctica y la teoría, al tiempo que la mayor parte de sus protagonistas vivieron su época como académicos, profesores y ciudadanos comprometidos con valores de progreso, ocupando algunos ${ }^{65}$ puestos de gestión pública de la educación (Piaget, Bruner, Freire) ${ }^{66}$ con el afán de llevar a los hechos sus ideas reformadoras. Innovadores que sabían que se enfrentaban a una enseñanza tradicional, tanto en la técnica de aprender como en el saber trasmitido, sostenidas más o menos directamente por ideologías y poderes de índole conservadora. Hoy las coordenadas son más complicadas, multidimensionales, pero no por eso la herencia recibida, que vamos a repasar someramente, ${ }^{67}$ es menos ineludible.

Es obligado comenzar por la hoy olvidada, y fundacional, New School del norteamericano John Dewey (1859-1952), de cierta influencia hasta la I Guerra Mundial, que predicaba, desde una filosofía ilustrada (el constructivismo kantiano), una educación más práctica que atendiese al interés del propio alumno, actuando el profesor como orientador, al tiempo que se oponía de manera ejemplar - incluso para hoy - a la escuela tradicional en cuanto a los fundamentos de su discurso y militaba socialmente en favor de las causas progresistas del momento.

La pedagogía de la liberación del brasileño Paulo Freire (1929-1997), socialista cristiano y humanista, próximo al marxismo, perseguido por los regimenes militares, abarcaba en su planteamiento renovador tanto la teoría como el método, denunciaba que no existía una pedagogía neutra y proponía una educación popular que tuviera por objeto crear una conciencia política entre

\footnotetext{
${ }^{64}$ En la medida en que no se logró en aquellos (véase la nota 73 ), necesitamos ahora volver de nuevo, como en una espiral, a la síntesis equilibrada.

${ }^{65}$ Otros iniciaron en la clandestinidad su lucha democrática por una nueva escuela como el movimiento de renovación pedagógica Rosa Sensat de Barcelona, todavía activo (véase la nota 111).

${ }^{66}$ Políticos y partidos buscaban, y buscan, académicos de las ciencias de la educación, para legislar y gestionar tan importante sector para cualquier Estado, poniendo a prueba reformas (y contrarreformas), generando de un modo u otro información valiosa sobre la relación entre política y pedagogía, modelos de sociedad y modelos didácticos, ineludible para situar nuestros debates, propuestas y reflexiones en su preciso contexto.

${ }^{67}$ Repaso necesario para los lectores que no estén especializados en didáctica o pedagogía.
} 
los oprimidos, buscando - igual que Dewey - un educando activo (respetando su autonomía y saberes, de los que habría de aprender el propio educador) en base al diálogo permanente entre profesor y alumnos (pedagogía de la pregunta).

La psicopedagogía cognitiva del psicólogo evolutivo y epistemólogo suizo Jean Piaget (1896-1980) se planteaba el interrogante de cómo los sujetos conocen, en sus diferentes estadios, e insistía asimismo en el papel activo del alumno, desechando la coerción como "el peor de los métodos pedagógicos", que proponía sustituir por el "ejemplo", así como cambiar los manuales por obras de referencia y educar de manera experimental, "probando uno mismo". Constructivismo psicológico, influido por Dewey, que sentenciaba: "Una verdad aprendida no es más que una verdad a medias mientras que la verdad entera debe ser reconquistada, reconstruida o redescubierta por el propio alumno" ${ }^{68}$

La teoría constructivista del aprendizaje del psicólogo estadounidense Jerome Bruner (1915-actualidad) precisa, siguiendo a Piaget, las estrategias cognitivas y de formación de conceptos en los alumnos, porfiando en el aprendizaje por descubrimiento, extrapolación y llenado de vacíos por parte del alumno, diálogo activo profesor-alumnos y currículo espiral, volviendo progresivamente sobre los contenidos, explicando estructuras antes que hechos y actores. Animador de la reforma educativa en los EE.UU. y asesor del presidente Kennedy, en un reciente viaje a Madrid ${ }^{69}$ manifestó soberanamente su fidelidad a un constructivismo ilustrado y liberal, ${ }^{70}$ nada que ver con el desencanto posmoderno, se mostró como un optimista ${ }^{71}$ (a los 92 años, lo que tiene más mérito) que no elude el compromiso. ${ }^{72}$ Bruner apuesta de entrada, como era de esperar, por la com-

\footnotetext{
${ }^{68}$ MUNARI, Alberto, Jean Piaget (1896-1980). Perspectivas: revista trimestral de educación comparada. París: Unesco, vol. XXIV, n 1-2, 1994, p. 315-332< tions/ThinkersPdf/piagets.PDF>.

${ }^{69}$ Donde aceptó asesorar en temas educativos al candidato socialista a la alcaldía de Madrid, prestándose a una entrevista en El País el 9 de abril de $2007<\underline{\text { http://www.elpais.com/articulo/ }}$ educacion/Hay/evitar/alumnos/aburran/escuelas/elpepuedu/20070409elpepiedu_5/Tes>.

70 "Enseñar las distintas maneras de pensar y los distintos mundos, distintas maneras"; "todos los hombres son creados iguales... El Estado no puede decirte en que creer", ídem.

${ }^{71}$ En contra de la opinión pesimista de muchos profesores sobre la educación en España, dice: "No estoy de acuerdo. Todo ha mejorado mucho. Se habla de ello en otros países. Sólo hay que volver un poco la vista atrás para comprenderlo"; y también contradice eso de que los alumnos españoles estén desmotivados: "los niños españoles tienen una enorme curiosidad... El problema es que... se aburren", ídem.

${ }^{72}$ Sobre la posición de la Iglesia española de que los alumnos aprendan obligatoriamente religión: "Yo tengo una mentalidad muy anglosajona, creo en la separación entre la iglesia y el estado... Cada uno debe elegir su propio Dios"; apoya la escuela para emigrantes, integrar la cultura lo-
} 
binación de competencias y conocimiento ${ }^{73}$ pero le interesa más, como a todos los constructivistas (herencia que la pedagogía de las competencias extremó al máximo) los métodos del aprendizaje que los contenidos de la enseñanza. ${ }^{74}$ Inclinación suprema por las técnicas de enseñanza ${ }^{75}$ fundamentada, justo es aclararlo, en criterios de eficacia pedagógica y no en la política economicista de sujetar la educación al mercado.

La Epistemología social de la educación de Lev Vigotsky (1896-1934), psicólogo bielorruso, marxista no ortodoxo, introduce el contexto social ${ }^{76}$ en el proceso educativo (con críticas a Piaget), difundiéndose en Occidente en los 60 y 70, e influyendo en Bruner (traductor de su obra principal al inglés) y otros modernizadores de la educación, tanto marxistas como constructivistas. Apoya el aprendizaje colectivo pero destaca aún más el papel de los mediadores, familia y sobre todo profesores, destinados a guiar al niño para que pueda desarrollar capacidades cognitivas.

En conclusión, como reacción a la didáctica tradicional, conductista y empirista, se desplegaron internacionalmente a lo largo del siglo XX dos grandes corrientes renovadoras, una cognitiva-constructivista y otra marxista, ${ }^{77}$ compartiendo ambas un paradigma común sobre una escuela anti-autoritaria, animadora

cal... pero con ciertos límites, no contesta directamente a la pregunta sobre educación y política, reduciéndose a reivindicar que "debatir es bueno" y exige más fondos para la enseñanza.

${ }^{73}$ Le preguntan “¿qué piensa del debate sobre si destrezas o contenidos”, y contesta: "Creo que la mejor manera de enseñar es utilizar ambas", "hay que pensar en qué conocimientos" pero también "el proceso de conocer", ídem.

74 “Hay que conseguir primero un entendimiento, una comprensión, unas formas y luego quizá intentar perfeccionar esos contenidos"; jerarquía de intereses constructivistas que, desequilibrando la síntesis prometida destrezas/contenidos, remata por dejar el tema de la reproducción del saber (contenidos) al Estado; preguntado por la nueva asignatura Educación para la ciudadanía, responde que conoce el actual debate Partido Popular/Partido Socialista Obrero Español, piensa que "la asignatura es buena idea" pero insiste una vez más que "lo que hay que ver y analizar es como enseñarla. Se puede enseñar de una manera estúpida o de una manera muy inteligente", valorando de nuevo la metodología antes que nada, ídem.

${ }^{75}$ Igual que pasa con la historia y otras compartimentaciones institucionales, fenómeno de fragmentación académica contra el que hay que luchar, la especialización en didáctica, deja de lado sin querer otros aspectos del proceso de conocimiento y enseñanza, y más todavía si la didáctica es de signo cognitivo-constructivista.

${ }^{76} \mathrm{La}$ interacción escuela y sociedad es hoy muy relevante que nunca por determinar problemas agudos de la enseñanza actual (multiculturalismo, drogas, desempleo, violencia, indisciplina etc.), sobre los que volveremos.

${ }^{77}$ La didáctica marxista de los 60 y 70 reprodujo de forma moderada (por la unidad de su objeto) el movimiento pendular, típico del marxismo del siglo XX, entre objetivismo (Vigostky, de influencia más académica) y subjetivismo (Freire, de influencia más político-social). 
de un aprendizaje colaborativo y sensible a su función social. Desconocer esta herencia, o descalificarla como "resabios sesentistas", ${ }^{78}$ es un claro indicio de la intencionalidad conservadora del nuevo paradigma educativo basado substancialmente en competencias, además del error práctico de subvalorar el grado de irreversibilidad de las aportaciones innovadoras de los años 60 y 70 . La experiencia del proyecto Tuning es significativa, al tener que introducir elementos de "educación en valores"79 y aceptar la diversidad de modelos didácticos en Europa, en su mayoría interesados por los contenidos; ${ }^{80}$ en contradicción con las directrices - inflexible en origen - sobre la "educación en competencias"81 de procedencia angloamericana, pero extrañas al constructivismo ilustrado de los pioneros norteamericanos John Dewey y Jerome Bruner.

Resumiremos, por último, algunas de nuestras reflexiones sobre esta tarea de recobrar de manera reivindicativa, pero autocrítica, la experiencia de las vanguardias pedagógico-didácticas del pasado siglo, al igual que hicimos con los paralelos movimientos historiográficos: ${ }^{82} 1$ ) la renovación pedagógica del siglo $\mathrm{XX}$, plural pero convergente, ha triunfado relativamente, ya que no estamos didácticamente en el siglo XIX, pero tampoco en los años anteriores y posteriores a 1968, y está a debate de nuevo lo esencial del qué, el cómo y el por qué enseñar la historia; 2) el cambio de contexto social, político y cultural de un siglo a otro, y la aceleración histórica que todavía estamos viviendo, engendra nuevas preguntas, trastoca muchas de las que nos hacíamos hace 40 o más años y restringe la eficacia de las viejas respuestas. Y mientras conservan cierta continuidad y se reubican las viejas contribuciones del constructivismo y el marxismo, surgen nuevas tendencias como la escuela posmoderna y empresarial de las competencias o la vuelta a la escuela tradicional (alimentada por las "historias oficiales" de tipo político y el retorno historiográfico correspondiente), coincidentes precisamente en su tentativa, en parte lograda, de minorizar la

\footnotetext{
${ }^{78}$ Véase la nota 6.

${ }^{79}$ Véase la nota 54.

${ }^{80}$ El acuerdo de la Comisión de Historia sobre el minicurrículo troncal europeo dice que hay que "aprovechar al máximo la rica diversidad de sus tradiciones en enseñanza, aprendizaje e investigación, es obvio que el principio fundamental ha de ser preservar dicha diversidad", Proyecto Tuning. Puntos comunes de referencia para los cursos y currículos de Historia, p. 172.

${ }^{81}$ Con todo, la capacidad de influencia del profesorado para forzar una síntesis circunstancial, no es la misma en la enseñanza media: los profesores de instituto enmiendan las orientaciones administrativas más bien en la fase de aplicación.

${ }^{82}$ Véase el punto X del Manifiesto historiográfico de Historia a Debate.
} 
veterana influencia marxista reconduciendo a su ex-aliado, el constructivismo liberal-progresista de Dewey y Bruner, hacia la competencia del mercado; 3) en tal tesitura, sobra cualquier nostalgia, autocomplacencia o actitud resistencial que nos impida entrar en el debate y las propuestas de los nuevos paradigmas del siglo XXI, adornando con citas rituales a las "nuevas escuelas", y sus representantes, que nos formaron la perplejidad que nos producen los nuevos desafíos y realidades, y nuestras propias prácticas; 4) el paradigma común constructivista y marxista cultivó en conjunto la teoría de la educación y la metodología del aprendizaje, la pedagogía y la didáctica, pero poco o nada el saber a trasmitir, el contenido de las materias a enseñar, algo fundamental y siempre polémico en el caso de la historia, dejando los saberes y su orientación a los especialistas correspondientes (los historiadores, en nuestro caso), la lucha cultural e ideológica (en la mejor de las hipótesis) y las autoridades administrativas, siempre celosas de sus prerrogativas en políticas educativas. De ahí que a los historiadores nos sonara como nuevo la reciente defensa, desde la didáctica de la historia, de una mayor conexión - incluso una alianza - de la historia enseñada con la historia investigada; ${ }^{83}$ ) a tenor de los problemas y avances acumulados, y de los tiempos que vivimos, el nuevo paradigma ha de ser global o no será. En contra del fundamentalista new paradigm de las competencias, con el apoyo de políticos neoliberales decididos en que la relación de la enseñanza y la universidad con la empresa sea el factor hegemónico de nuestro futuro educativo, es factible y urgente un nuevo paradigma - que significa consenso, no lo olvidemos - que se sostenga en la amplia sociedad académica de los profesores y los historiadores. ${ }^{84}$ Articulando el papel activo de los alumnos y el nuevo protagonismo de los profesores, los saberes y las competencias, los valores y las ciencias, las actividades digitales y presenciales. Un nuevo consenso didáctico-historiográfico que genere ideas nuevas para problemas nuevos y reformule nuestras mejores tradiciones, vertebrando lo más interesante y novedoso en historia, didáctica, pedagogía y organización escolar (empleo selectivo del tiempo), sin olvidar la dignificación del oficio de profesor de historia, en todos los estadios.

\footnotetext{
${ }^{83}$ Véase la nota 11, y también VALLS, Rafael. Conciencia histórica y enseñanza de la historia (en la educación obligatoria). Historia a Debate. Nuevos paradigmas, tomo II, 2000, p. 178.

${ }^{84}$ Lo que ya está sucediendo una gran parte de las ideas aquí expuestas para el debate son mantenidas en conjunto o por separado por otros profesores, historiadores y especialistas en didáctica o pedagogía, lo sabemos porque los hemos oído y leído.
} 


\section{Aprender con fuentes}

Un beneficio "inesperado" para los estudios de historia en la enseñanza secundaria de la educación por competencias es el impulso que supone del trabajo con fuentes de los alumnos. En realidad el constructivismo, según vimos (Piaget), ya había planteado la necesidad de educar experimentalmente, y las ciencias de la naturaleza lo venían y vienen practicando. Lo nuevo es que, al ser de aplicación general el axioma sagrado de las competencias, se fomente "desde arriba" una formación temprana de los alumnos de historia en el trabajo con fuentes, algo específico de los historiadores de oficio, que, paradójicamente, tienen su futuro profesional como tales mayormente en la función pública, fuera del mercado. ${ }^{85}$

Naturalmente, el profesor de enseñanza media no puede orientar a los alumnos en el trabajo con fuentes (escritas, orales, arqueológicas, patrimoniales, iconográficas, audiovisuales) sin un mínimo de información histórica y contextual sobre el tema, en papel o en red, lo que reafirma la alianza didáctico-historiográfica de que hablamos, que encuentra así un nuevo campo de convergencia entre historia enseñada e historia investigada: un paso adelante, en definitiva, para garantizar al mejor nivel la continuidad del proceso de conocimiento histórico desde la universidad a la ciudadanía, y viceversa.

El aprendizaje del alumno por sí mismo, manejando fuentes semejantes a las utilizadas por los historiadores, implica nuevas exigencias y posibilidades al profesorado: ${ }^{86}$ formación historiográfica continua; mayor conexión educación / investigación, enseñanza media / universidad: ${ }^{87}$ y promoción, a todos los efectos, de la figura del profesor-investigador en las enseñanzas medias. ${ }^{88}$ Procurando

\footnotetext{
${ }^{85}$ Últimamente surgen pequeñas empresas de jóvenes historiadores que ofrecen a particulares e instituciones servicios de paleografía, búsquedas en archivos, publicaciones, pequeñas investigaciones y gestión cultural, fenómeno interesante de historia aplicada (y fuente de salidas laborales) que habremos de divulgar y desarrollar, si bien ello no contradice la realidad - que reivindicamos - del carácter mayoritariamente público, en cuanto a financiación y objetivos, de la investigación profesional y de la enseñanza de la historia.

${ }^{86} \mathrm{Al}$ profesor de secundaria se le exige ahora más formación, actividad docente y conocimientos como investigador, al tiempo que es ninguneado en su función social y docente por la frecuente desatención en la práctica, por parte del Estado, y en la teoría por la "novedad" de los facilitadores. ${ }^{87}$ La Universidad Nacional Autónoma de México, por ejemplo, integra en su seno la enseñanza

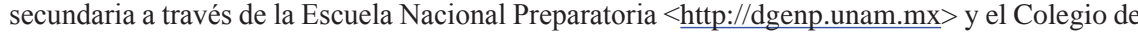

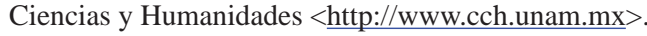

${ }^{88}$ Que debería serle permitido y facilitado continuar su carrera docente e investigadora en la enseñanza superior, como reivindican los sindicatos de profesores.
} 
formas nuevas de institucionalización de la ampliación de la comunidad académica de historiadores, desde la óptica bidireccional que venimos practicando en Historia a Debate. ${ }^{89}$ Integrar más y mejor el profesorado de medias junto con el profesorado de universidad, en el ámbito de la investigación, es una necesidad objetiva de la funcionalidad y calidad del proceso educativo e investigador ${ }^{90}$ que - cuanto menos en España - no ha reclamado todavía la atención de los poderes públicos.

Un sistema educativo que pretende poner el acento en las destrezas laborales para facilitar la inserción en el mercado, al aplicarse a las humanidades y las ciencias sociales se encuentra con que tiene que centrarse en desenvolver destrezas intelectuales, sobre todo cuando se trata de disciplinas ajenas al mundo de la empresa, la tecnología o las ciencias aplicadas, con una función pública y social vinculada al saber, que los planes $\mathrm{I}+\mathrm{D}+\mathrm{i}$ suelen confinar en lo que denominan "promoción general del conocimiento". Ahí es dónde se puede hacer rentable, de rebote, para la historia y demás "saberes improductivos" - según la ortodoxia neoliberal - la educación en clave de competencias, que planteada necesariamente alrededor de competencias intelectuales resulta más compatible con una educación en valores críticos, solidarios y democráticos. En suma, el nuevo paradigma de competencias, conocimientos y valores, que preconizamos es más viable en historia que en otras materias menos "marginales", para el "gran hermano" competencial. El autoaprendizaje con fuentes, bajo la guía del profesor, puede reunir de entrada cierto consenso entre las viejas y nuevas tendencias didáctico-pedagógicas, marxismo, constructivismo y “educación por competencias" siempre que el interés por las fuentes vaya parejo con el interés por los contenidos y los valores, para lo cual es indispensables evitar y seguir combatiendo la "idolatría de las fuentes" de que hablaba Marc Bloch.

La adquisición de habilidades historiográficas por parte de los alumnos de la escuela secundaria enseña al estudiante cómo se hace la historia, adoptando el punto de vista del autor - en lugar de lector - ante los libros de historia, lo que no siempre se consigue en la universidad. Desarrollando así un verdadero por autoaprendido - sentido crítico sobre la escritura de la historia, de especial

\footnotetext{
${ }^{89}$ Véase la nota 20.

${ }^{90}$ Una parte creciente de las tesis doctorales de historia leídas en la universidad española son ya realizadas por profesores de historia en la enseñanza media, y tienen la ventaja añadida de ser con frecuencia obra de investigadores experimentados.
} 
valor cuando se trata de historias oficiales, presentes por ley y/o el principio de autoridad académica, en las asignaturas de historia.

La aptitud asumida precozmente para familiarizarse con diversos tipos de fuentes, extraer datos, contextualizar unas y otros y participar incluso en la redacción y discusión de los resultados, por muy elemental que sea, desmitifica el trabajo del historiador, identifica tendencias, prepara mejor al estudiante para la enseñanza superior, animando vocaciones para los estudios universitarios de historia, destrabando el camino para profundizar en la educación con fuentes en la universidad, donde todavía predominan los trabajos puramente bibliográficos de los alumnos. Habrá para ello, por consiguiente, que sacar experiencias de la parte positiva del modelo anglosajón (inglés y nórdico, sobre todo), sin dejar los contenidos de la historia a la escuela secundaria, ${ }^{91} \mathrm{o}$ a decidir por no se sabe quién.

El trabajo con fuentes puede orientarse según la idea decimonónica de Langlois y Seignobos de que la "historia se hace con documentos" (escritos, por supuesto) y punto, o aceptar la diversificación de fuentes escritas, desde el documento oficial hasta la literatura coetánea, pasando por las fuentes orales, la cultura material y las fuentes artísticas, audiovisuales y digitales. Educar con fuentes, y una bibliografía mínima, comporta a estas alturas una triple actualización historiográfica: enseñar la historia como una "ciencia con sujeto", procurar aproximaciones globales y analizar el presente a la manera de los historiadores. ${ }^{92}$

Es menester combatir desde la escuela - sin echar el niño con el agua sucia - el mito positivista de que el uso de fuentes asegura conocer la verdad histórica "tal como fue" (Ranke). Trasmitiéndole un concepto actualizado de ciencia, el alumno ha de aprender que la verdad de la historia que escribimos está condicionada, no sólo por el contexto actual y los intereses políticos y sociales, ${ }^{93}$ sino también por el propio historiador. ${ }^{94}$ Ubicando la comunidad de

\footnotetext{
${ }^{91}$ Contenidos en secundaria - memorizando, seguramente - y competencias en la universidad, opción contradictoria con las supremas "competencias básicas", avalada curiosamente - en aras de la diversidad, suponemos - por el proyecto Tuning, véase Puntos comunes de referencia para los cursos y currículos de Historia, p. 170-171.

${ }^{92}$ Véase las referencias de las notas 2 y 10.

${ }^{93}$ Proyecto Tuning, p. 173.

${ }^{94}$ Lo que no quiere decir que la historia que hacemos sea mentira, las fuentes junto con la interpretación, experiencia y rigor del investigador, garantizan una conocimiento cierto pero revisable, opinable y superable, parcial; parcialidad y precisión no son antitéticos: el sesgo de una obra de historia suele venir del enfoque historiográfico aplicado, los valores del propio autor, la propia intencionalidad de su investigación (académica, mediática, política, religiosa...); de ahí que sea necesario combinar a menudo diversas fuentes bibliográficas (y diferentes fuentes primarias, cada
} 
aprendizaje, y ante todo el sujeto docente, entre los participantes de la escritura continua, plural y comunitaria, de la verdad histórica, que también está fundada en ideas e imaginación, ${ }^{95}$ haciendo realidad el enunciado: el historiador descubre su objeto conforme lo construye y enseña. ${ }^{96}$

Enseñar a pensar la historia de manera global, en la doble acepción de mundial y total, ${ }^{97}$ es una reclamación de nuestro tiempo y una estrategia de futuro. La revolución de las comunicaciones nos está habituando a percibir y sintetizar información diversa, paradójica ${ }^{98}$ y compleja, la historia investigada y enseñada no puede ir a la zaga, ha de analizarse y aprenderse de manera también diversa, paradójica y compleja, interrelacionando niveles, factores y actores, involucrando fuentes de diferente tipo y parcialidad, ensayando explicaciones de conjunto. Para lo cual tenemos que practicar la reivindicada intradisciplinaridad entre especialidades historiográficas (enlazadas en algunos casos con otras disciplinas), que ponga en evidencia la capacidad investigadora y didáctica de la historia para integrar otras ciencias sociales. ${ }^{99}$ Tenemos que confesar, de todas formas, que el problema de la parcelación del saber histórico está más en la investigación, día a día más especializada ${ }^{100}$ que en la historia enseñada, cuando epistemológicamente debería ser lo contrario: nuestro sistema universitario e investigador sigue estimulando en la práctica la especialización cronológica y temática. ${ }^{101}$ Conseguir aproximaciones más globales de la historia ${ }^{102} \mathrm{es,} \mathrm{por} \mathrm{lo}$

una con su parcialidad específica).

95 "La historia se hace con documentos y con ideas, con fuentes y con imaginación". LE GOFF, Jacques. Tiempo, trabajo y cultura en el Occidente Medieval. Madrid, 1983, p. 7.

${ }^{96}$ Véase Por un nuevo concepto de la historia como ciencia en www.h-debate.com/Spanish/ presentaciones/lugares/quito.htm.

97 "Historia total" tal como la entendieron el marxismo y la escuela de Annales, noción historiográfica que apremia retomar ahora, con nuevos enfoques, formas y métodos, ante el imparable avance de la fragmentación (véase al punto 5 de Manifiesto historiográfico de Historia a Debate).

${ }^{98}$ Etimológicamente la palabra 'paradoja' significa lo "contrario a la opinión recibida y común", estado de opinión bastante determinada - todavía - por el principio cartesiano de no contradicción; se dice corrientemente que una expresión es paradójica porque contiene elementos contradictorios, y de manera más avanzada se entiende por paradoja es una falsa o aparente contradicción, según la nueva lógica trans-racional.

${ }^{99}$ Véase la referencia de la nota 39.

${ }^{100}$ Véase Historia a Debate, un paradigma global para la escritura de la historia en www.h-debate. com/congresos/3/videos/menu.htm.

${ }^{101}$ La parcelación de la historiografía académica sigue siendo un grave problema - falta de hilo conductor y enfoque común - a la hora de publicar historias generales de ámbito regional, nacional, europeo e universal, sea para la enseñanza sea para una difusión más amplia.

${ }^{102}$ Véase la referencia de la nota 15. 
tanto, una cuestión pendiente que han de resolver, de manera interrelacionada, los nuevos paradigmas de la historia y de su enseñanza.

La necesidad de educar de manera global, en el siglo de la globalización, es presentada en los Estados Unidos, como otra variante del nuevo paradigma de la enseñanza, denominada "educación holística", ${ }^{103}$ al margen de la educación por competencias (que no suelen nombrar). Esta propuesta parte de una ética humanista de inspiración religiosa, ${ }^{104}$ es crítica con "la visión reduccionista cognoscivista considerando al ser humano en su totalidad" y se apoya - justamente - en la ciencia de la complejidad para justificar el cambio de paradigmas y definir el concepto de totalidad. ${ }^{105}$ Nuestra posición es llevar el holismo más allá: enseñar nueva historia global (contenidos); incluir el hombre educando y educador como parte de la humanidad, social y políticamente organizada (valores); asumir que estamos en una economía de mercado, que rige - parcialmente - la oferta y demanda laboral y profesional (competencias), aunque tal regulación económica incumbe menos a la historia que a otras materias.

Nuestra tercera propuesta de actualización historiográfica educativa guarda relación con la historia inmediata: comprender el presente desde una óptica histórica, examinar los hechos actuales o recientes de relevancia histórica, empleando fuentes directas (prensa, TV, Internet) y el propio testimonio y opinión de los miembros de la unidad de aprendizaje. Demostrando que la historia no es solamente "cosa del pasado" y que también ellos hacen la historia, formando mejor de este modo a los futuros ciudadanos como sujetos históricos.

No se trata únicamente de poner ejemplos de actualidad para interesar en los alumnos sobre la historia pasada, evitar el aburrimiento y lograr mayor participación (todo el mundo tiene algo que decir sobre hechos que están sucediendo), lo que no es poco, sino de asumir una novedad historiográfica, el consenso creciente entre los historiadores más avanzados acerca de la inclusión del mismo presente, o de hechos recientes que cambian la visión del pasado

\footnotetext{
${ }^{103}$ El holismo considera el "todo" distinto de las "partes": una buena idea, pues, para rebatir a aquellos que, instalados en su propio fragmento, consideran "eclecticismo" (término antidialéctico que quiere decir adoptar posiciones intermedias o conciliar opuestos) todo intento de reconstruir totalidades, lo que se descalifica como pretensión "utópica".

${ }^{104}$ Los valores laicos y religiosos son obviamente conciliables y legítimos, han de formar parte de una escuela plural en una sociedad democrática, siempre y cuando se respete la separación Iglesia / Estado y la preeminencia del poder público y sus leyes.

${ }^{105}$ Más información en http://www.geocities.com/ed_holista/index.htm (castellano), http://www. holistic-education.net (inglés).
} 
(historiografía inmediata), en nuestro objeto de investigación, y por lo tanto de docencia. ${ }^{106}$ Como consecuencia de la celeridad histórica propia de nuestra época, y de la instantaneidad de la sociedad de la información, el presente se hace inmediatamente pasado. Nos queda corto ahora lo de entender el presente por el pasado, y el pasado por el presente, se puede y se debe investigar y comprender la propia actualidad con la metodología (adaptada) de los historiadores, a sabiendas de que el proceso que estudiamos está inacabado, y que por fuerza toda investigación de historia inmediata es participativa, sujetas a revisiones futuras, como toda historiografía y didáctica pluralista y comprometida. ${ }^{107}$ Transformar la novedad historiográfica (en proceso de debate y aplicación) en novedad didáctica, debatir (entre los profesores y con los alumnos) dicha proposición, llevarlo a la práctica en el aula, divulgando los resultados, e incorporar experiencias de historia del presente, actual, reciente o inmediata, remontándose tan atrás como haga falta, en las ponencias de innovación docente que solemos presentar en los congresos. La historia que enseñamos ganará con ello, con toda seguridad, en actualidad y cercanía.

\section{Educar en valores}

Una de las cuestiones clave que tiene que resolver el nuevo paradigma educativo es encontrar una interrelación, coherente y eficiente, entre la "educación en competencias" y la "educación en valores". ${ }^{08}$ Sinergia más problemática en el ámbito europeo que en los ámbitos nacionales, por la crisis de valores (Europa de los mercaderes vs. Europa social) y de perspectiva política por la

\footnotetext{
${ }^{106}$ Para introducir la historia inmediata, de manera institucional, hay que dar la batalla de los contenidos, prolongando la historia de España y la historia contemporánea en verdad hasta el mundo actual, cuando menos hasta el $11 \mathrm{~S}$ y la guerra de Irak, el 11 M y la recuperación de la memoria histórica, poniéndolo en práctica desde ya en nuestras clases.

${ }^{107}$ En América Latina, por la propia efervescencia histórica que están viviendo una serie de países, y el alto grado de compromiso por parte de no pocos historiadores, la historia inmediata parece estar más al día que en Europa, de hecho el concepto de historia inmediata de Historia a Debate se ha basado originalmente en ejemplos latinoamericanos, véase ¿Es posible una historia inmediata? en www.h-debate.com/cbarros/spanish/articulos/mentalidades/inmediata.htm.

${ }^{108}$ En esto el fracaso del proyecto Tuning es claro, como ya vimos, al introducir por la puerta pequeña la educación en valores, como resulta evidente incluso para sus defensores más inteligentes: "Hubiera sido de desear que el propio proyecto hubiera colocado al menos al mismo nivel la educación en competencias y la educación en valores y hubiera hecho explícitos algunos valores definitorios de la identidad europea a la que se aspira, pero no ha sido así”. TUDELA, Pío, y otros, Las competencias en el nuevo paradigma educativo para Europa, p. 11, disponible en www.ugr. es/ psicolo/docs espacioeuropeo/analisis de competencias europa.doc.
} 
que atraviesa la construcción europea, imposibilitada por el momento de dotarse de una verdadera Constitución. Mientras que los Estados que financian la enseñanza obligan, en diverso modo y grado, a que ésta siga los criterios políticamente correctos, marcados por la Constitución, y sean útiles para promover las identidades nacionales, con lo que la enseñanza pública no puede obviar, como sueñan en sus nubes los didactas neoliberales, la educación en valores, especialmente las ciencias humanas y sociales.

Dicho de otro modo, la concepción de hacer girar, principal y soberanamente, la educación del siglo XXI sobre las competencias laborales o empresariales está abocada al fracaso, ${ }^{109}$ por razones funcionales, legales y de mentalidad, en los países donde existe un marco democrático estable y un fuerte poder público, un Estado de bienestar y una sociedad civil activa. Los valores que subyacen en la idea original de competencia, destreza o habilidad, como subordinación del aprendizaje al mercado de trabajo, ${ }^{110}$ se ocultan precisamente porque chocan frontalmente con valores esenciales de la enseñanza pública ${ }^{111}$ y con la razón de ser de la propia universidad. En nuestra opinión, sólo una "educación en competencias y valores", o "en valores y competencias", según la inclinación que se le quiera dar, pueda alcanzar el consenso suficiente en las comunidades educativas para poder hablar de un mayoritario y eficaz "nuevo paradigma educativo" (que tiene su tercera pata en la "educación en contenidos", que siguen siendo imprescindibles, trufados eso sí de competencias y valores). Único modo además de conciliar en la teoría y en la práctica el papel activo de los alumnos, objeto de las competencias, con el papel activo del profesor, sujeto principal de los valores y de los contenidos.

La reciente implantación en España por ley, y en otros países europeos, de una asignatura específica de "Educación para la ciudadanía", no exime más bien lo contrario - la enseñanza de la historia y otras ciencias sociales y

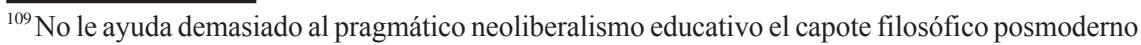
con sus elevadas dosis de pesimismo y desencanto ante la crisis de una enseñanza publica que tiene en la modernidad y la ilustración sus bases primigenias, lo que no debería olvidarse.

${ }^{110}$ Por tratarse de competencias intelectuales y heurísticas, los efectos nocivos de la subordinación al mercado de la enseñanza de la historia, y de otras ciencias sociales, son más bien indirectos: infravaloración de los grandes valores y de sus depositarios; desequilibrio de medios y horas de clases a favor de materias de mayor utilidad "práctica"; desarrollo de universidades privadas, que eliminan de sus planes de estudio los estudios histórico-sociales, en detrimento de las públicas. ${ }^{111}$ Sirva de referencia el Manifiesto Por una educación pública (Barcelona, 2005), del movimiento de renovación pedagógica Rosa Sensat, que actualiza el texto con el mismo título de $1975<\underline{\text { http:// }}$ www.rosasensat.org/Declaracion.pdf>.
} 
naturales, sobre la base de valores universales de paz y democracia, justicia e igualdad, tolerancia y pluralismo, derechos humanos, de género y opción sexual, respeto del medio natural así como de las diferentes identidades étnicas, religiosas y nacionales. Derechos y deberes que no se comprenden sin aprender historia, maestra de vida, partiendo de la experiencia individual y colectiva de los alumnos. La finalidad, en este caso, no es ya adquirir ya tanto destrezas como debatir e interiorizar convicciones morales, políticas y sociales, con la participación activa de los alumnos, sin que el profesor deba mostrarse neutro tratándose de valores y criterios fundamentales para una educación sana y tolerante, democrática y humanista, ilustrada y sostenida por la verdad histórica que conocemos.

Ya precisamos que el simple uso de fuentes históricas no llega para definir la verdad histórica, cuenta y mucho la selección de temas, enfoques y fuentes, la forma de obtener los datos, siempre interpretables de suerte diversa... Ahora bien, pluralidad historiográfica no quiere decir que "todo vale" por igual en rigor y valores. No se puede ocultar que el descubrimiento de América por parte de españoles y portugueses fue una conquista colonial, por mucho que se valore, aquí y allá, lo que tuvo de positivo para los americanos - y más todavía para las metrópolis - el encuentro de las dos civilizaciones. No se puede ocultar que el golpe militar en España del 18 de julio de 1936 fue un levantamiento contra un gobierno democráticamente elegido, que desató una cruenta guerra civil, una feroz represión y una larga dictadura, por mucho que se respete la opinión contraria (reactivada últimamente por parte de una neoderecha no académica), y se busquen los antecedentes históricos de las dos Españas, que explican pero no legitiman el franquismo. Sobra decir que una historia enseñada desde valores universales, desde un punto de vista actual, hace necesario también una historia investigada desde valores deontológicos para que nadie pueda instrumentalizarla para justificar lo injustificable.

Los valores escolares no surgen espontáneamente de los alumnos, obligan a una orientación del profesor, textos de referencia, prácticas y debates..., cuando menos para dar a conocer las opciones e interpretaciones principales, y sus consecuencias, en el caso de temas polémicos. Si hace un tiempo esta educación en valores fue deseable, hoy es impostergable para hacer frente con éxito a los problemas que asedian a la enseñanza obligatoria, inducidos en buena parte por una sociedad en proceso de cambio: fracaso escolar, indisciplina; violencia, acoso, drogadicción; desempleo, familias desestructuradas; inmigración, mul- 
ticulturalismo; brecha social y digital. En un contexto así, ¿en qué cabeza cabe que la solución a la crisis de la escuela - y a la desmotivación y el cansancio de los profesores - pasa por las competencias mercantiles y los facilitadores?

\section{Aula en red}

En trance de concluir estas reflexiones y propuestas en pro de un nuevo paradigma educativo que no se imponga administrativamente, que tenga en cuenta la situación real de la enseñanza, nuestras mejores tradiciones y la opinión colectiva del profesorado de secundaria, extrañará que no haya hablado todavía de Internet, ${ }^{112}$ cuyo uso en la enseñanza alcanza ya cierto nivel de acuerdo sobre su importancia entre profesores y especialistas en didáctica, cuestionándose más que nada la falta de formación, ganas, medios y tiempo para hacer de las clases de historia una escuela sin fronteras: una aula en red.

El motivo de dejar el paradigma digital para el final es evitar que el lector piense que el uso de las nuevas tecnologías de la información y la comunicación (TIC) es la nueva receta para el déficit de innovación docente. La verdad es que, como argumentamos antes, el nuevo paradigma educativo es global, en el sentido de integral, o no será, tampoco en lo digital: la innovación no puede ser parcial. Se puede navegar mucho por Internet (competencia digital) e ir retrasado en el resto: saberes y valores. De hecho un número importantes de las webs de historia, algunas entre las más visitadas, propagan contenidos tradicionales típicos de una historia de grandes hombres, batallas y acontecimientos; escaseando las que muestran algún interés por los métodos y enfoques historiográficos, y sus debates actuales. De qué vale pues asimilar y ejercitar la habilidad técnica para acceder a la información en Internet, si no se aprende a valorar y discriminar los datos obtenidos. En resumen: TIC más contenidos más valores; autoaprendizaje del alumno más instrucción del profesor para que nadie se pierda en la telaraña.

Por lo demás, aprender a moverse en la red, el uso de buscadores y otros recursos para consultar información, fuentes, imágenes y bibliografía, sobre un

\footnotetext{
$\overline{{ }^{112} \text { Más aún considerando mi función de coordinador de la red temática Historia a Debate }<\text { www.h- }}$ debate.com>, que "reúne" cada día digitalmente a ocho mil historiadores, profesores y estudiantes de historia de todo el mundo; y cuya página web ha tenido cerca de cuatro millones de visitas totales, desde 1999, y mantiene precisamente, desde 2000, entre sus debates uno sobre "¿Qué historia enseñar en el siglo XXI?" donde ha habido ya 114 participaciones de historiadores y profesores de diversos países a día de hoy (25/9/07).
} 
tema histórico determinado, participar en las redes temáticas de la Web 2.0, es una competencia básica para los alumnos de hoy y para nada aburrida para estas nuevas generaciones. Forma ideal, por otro lado, para alargar la comunidad de aprendizaje al mundo entero, promover la autonomía del alumno y acceder a novedades ${ }^{113}$ y materiales que no están disponibles a menudo en formato papel, más caro y menos accesible.

Evidentemente, la competencia informática y comunicativa por Internet, y otras tecnologías digitales, es tarea de la escuela en su conjunto, pero su utilización en las clases de historia depende sobremanera del desarrollo de experiencias concretas y recursos específicos, de lo que se han dado buenos ejemplos en este seminario de innovación docente de la Taula d’Història de la Universidad de Barcelona.

\section{Referencias de bibliografía}

AA. VV. Manifiesto historiográfico de Historia a Debate, disponible en portugués del Brasil. Disponible en http://www.h-debate.com/Spanish/manifiesto/manifiesto had.htm.

AGUERRONDO, Inés. Un nuevo paradigma de la educación para el siglo XXI. Reformas educativas en Argentina y Canadá. Trama social, gestión y agentes de cambio. Buenos Aires, 2000. Disponible en http://www.oei.es/administracion/ aguerrondo.htm.

BARROS, Carlos. El paradigma común de los historiadores del siglo XX. Medievalismo. Madrid, $\mathrm{n}^{\circ}$ 7, 1997. Disponible en http://www.h-debate.com/cbarros/ spanish/paradigma_comun.htm.

BARROS, Carlos. El retorno de la historia. Historia a debate. I. Cambio de siglo. Santiago de Compostela: Historia a Debate, 2000, p. 153-173. Disponible en www.h-debate.com/cbarros/spanish/articulos/nuevo paradigma/retornohistoria.htm.

BARROS, Carlos. La nuova storiografia e l'insegnamento della storia. Storia e Futuro. Revista de Storia e Storiografia. Bologna, n 5, ottobre de 2004.

BARROS, Carlos. Nuovi paradigmi della ricerca storica. Storiografia e insegnamento della storia: è possibile una nuova alleanza? Bologna, 20 de octubre de 2004. Audio disponible en http://www.h-debate.com/Spanish/presentaciones/ lugares/bologna.htm.

BARROS, Carlos. La historia mixta como historia global. Enfoques. Revista de

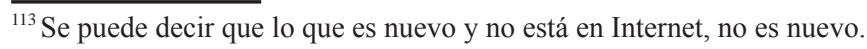


la Universidad Adventista del Plata. Argentina, año XVIII, $\mathrm{n}^{\circ}$ 1-2, 2006, $\mathrm{p}$. 91-118. Disponible en http://www.h-debate.com/cbarros/spanish/articulos/ historia_medieval/mixta.htm.

GARCÍA FERNÁNDEZ, Jorge Felipe. Algunas consideraciones acerca del proyecto Tuning Educational Structures in Europe. Disponible en http://firgoa.usc.es/ drupal/node/25877.

MATTOZZI, Ivo. Le ragioni di un convegno internazionale. Disponible en http:// www.storiairreer.it/IRRE/materiali/PresentazioneStoriografia04.rtf.

MCCLELLAND, David. Testing for competence rather than for intelligence. American Psychologist. Washington: American Psychological Association 1973, $\mathrm{n}^{\circ} 28$.

MUNARI, Alberto. Jean Piaget (1896-1980). Perspectivas: Revista Trimestral de Educación Comparada. París: Unesco, vol. XXIV, nº 1-2, 1994, p. 315-332. Disponible en www.ibe.unesco.org/publications/ThinkersPdf/piagets.PDF.

PAGÈS, Joan. Un itinerario por el mundo de las competencias en ciencias sociales, geografía e historia a través de los distintos currículos. Iber. Didáctica de las Ciencias Sociales, Geografía e Historia. Barcelona, n 52, 2007, p. 29-39.

SANMARTÍN, Israel. The end of History looking back and thinking ahead. In: BARROS, Carlos and MCCRANK, Lawrence J. (eds.) History under Debate. International reflection on the discipline. New York: The Haworth Press, 2000.

TUDELA, Pío, y otros. Las competencias en el nuevo paradigma educativo para Europa, p. 11. Disponible en www.ugr.es/ psicolo/docs espacioeuropeo/analisis_de_competencias_europa.doc.

VALLS, Rafael. Conciencia histórica y enseñanza de la historia (en la educación obligatoria). Historia a Debate. Nuevos paradigmas. Santiago de Compostela: Historia a Debate, tomo II, 2000. 